\title{
FISICALISMO E O PROBLEMA MENTE-CÉREBRO: UMA QUESTÃO DE DEFINIÇÃO
}

PHYSICALISM AND THE MIND-BRAIN PROBLEM:

A MATIER OF DEFINITION

\author{
JULIO CÉSAR MARTINS MAZZONI ${ }^{1}$ \\ Universidade Federal de Juiz de Fora (UFJF) - Brasil \\ julio.mazzoni@ich.ufjf.br
}

RESUMO: O Fisicalismo tem sido a posição filosófica monista mais aceita no mainstream do debate contemporâneo sobre a natureza do mental. Mas o que significa dizer que tudo o que existe é "físico"? O presente trabalho busca responder à pergunta: Como as teses fisicalistas contemporâneas têm definido o termo 'físico' em suas proposições? Para respondê-la foi realizada uma investigação teórico-filosófica baseada em revisão bibliográfica e análise lógica e conceitual. Quatro categorias gerais de definição do termo 'físico' foram identificadas numa revisão da literatura. Existem igualmente fortes críticas às propostas de definição em toda a discussão filosófica. Não temos uma definição incontroversa do que seja uma propriedade física, tampouco consenso sobre qual deveria ser a formulação mais adequada da tese fisicalista. Assim, a questão que se coloca é: Por que estamos discutindo o valor de verdade de uma tese que nem mesmo tem conseguido ser formulada de forma adequada?

PALAVRAS-CHAVE: Materialismo. Fisicalismo. Filosofia da Mente. Matéria. Físico.

ABSTRACT: Physicalism is the most widely accepted position in the mainstream of contemporary debates about the nature of mind. However, what does it mean to say that everything is physical? This paper aims to answer the question: How do contemporary physicalists define the term 'physical' in their propositions? To answer this question I performed a bibliographic review together with conceptual and logical analysis. Four sorts of definition of "physical" were found, and all have been the target of strong criticism. We do not have an uncontroversial definition of what a physical property is, nor a consensus on what the most appropriate formulation of the physicalist thesis should be. So the question that arises is: Why are we discussing the truth-value of a thesis that has not even managed to be properly formulated?

KEYWORDS: Materialism. Physicalism. Philosophy of mind. Matter. Physical.

"Aquilo que se sabe quando ninguém nos interroga, mas que não se sabe mais quando devemos explicar é algo sobre o que se deve refletir"

(WITTGENSTEIN, Investigações Filosóficas, 『 89)

\footnotetext{
${ }^{1}$ Doutorado em Psicologia pela Universidade Federal de Juiz de Fora (UFJF).
} 


\section{INTRODUÇÃO}

Qual é a natureza da mente humana? Seria a mente somente um produto derivado de processos cerebrais ou parte de uma alma imaterial interagindo com o corpo? Como o mental se relaciona com o físico? Tais questões intrigaram os seres humanos durante séculos e fazem parte hoje do chamado problema mentecorpo, discutido historicamente no âmbito filosófico e atualmente em áreas fronteiriças do conhecimento, como a Psicologia, a Neurociência e a Psiquiatra. É a questão ontológica central da Filosofia da mente, campo de investigação filosófica sobre a natureza do mental, e um dos tópicos mais debatidos na contemporaneidade.

O problema mente-corpo (atualmente mente-cérebro) já foi considerado um problema composto por um aglomerado de questões inter-relacionadas, contendo aspectos de natureza científica, epistemológica, sintática, semântica e pragmática, intimamente associados com questões filosóficas controversas como a teleologia, a intencionalidade e o livre arbítrio, assim como o extremo oposto, ou seja, um pseudoproblema (Scheinproblem), uma falsa questão (FEIGL, 1967).

Diferentes tentativas de respostas ao problema foram e continuam sendo oferecidas pelos mais diversos pensadores ao longo do tempo (ARMSTRONG, 1993; CHURCHLAND, 1981; DENNETT, 1996; FODOR, 1981; PLACE, 1956; POPPER \& ECCLES, 1977; PUTNAM, 1967; RYLE, 1949; SEARLE, 1992; SMART, 1959; SWINBURNE, 1986). Qual é o estado do debate na atualidade? A possibilidade de uma resposta inequívoca para essa pergunta não é clara. Não obstante, temos um panorama, partindo de um ceticismo sobre a possibilidade de resposta ao problema, em função dos limites de nossa capacidade de conhecimento (McGINN, 1989), passando por inúmeras possibilidades de respostas concorrentes, até uma forte adesão ao Fisicalismo como melhor alternativa explicativa.

O fisicalismo tem sido a posição filosófica mais fortemente defendida e aceita no mainstream do debate atual sobre a natureza da mente (KIM, 2006), chegando a ser considerada a Weltanschauung da Filosofia contemporânea (GILLET \& LOEWER, 2001). Numa recente pesquisa, Bourget e Chalmers (2014) constataram que 56\% dos filósofos profissionais dos principais departamentos de filosofia do mundo consideram o fisicalismo a melhor opção frente à questão ontológica sobre o problema mente-corpo, 16\% acreditam em outras alternativas e somente $27 \%$ responderam sustentar um anti-fisicalismo.

No estado atual do debate, os esforços têm focado na tentativa de demonstrar como a mente pode ser derivada de um estado físico, portanto, o escopo geral seria fornecer uma compatibilização do fenômeno mental com a visão de mundo fisicalista (MONTERO, 2001; KIM, 1998). Entretanto, igualmente, o fisicalismo tem sido alvo de críticas e questionamentos em razão das dificuldades teóricas encontradas para lidar com problemas filosóficos, tais como a consciência fenomenal e os qualia, a intencionalidade do mental, o problema do significado e a irredutibilidade do mental (CHALMERS, 1995, 1996, 2002; JACKSON, 1982, 1986; KOONS \& BEALER, 2010; LEVINE, 1983; NAGEL, 1974; ROBINSON, 1996). O movimento de antítese às teses fisicalistas vem crescendo, não se restringindo 
apenas à dimensão filosófica, mas também alcançando o domínio mais amplo da atividade empírica e científica (BEAUREGARD et al., 2014; GREYSON, 2010; PARNIA, 2007; SHELDRAKE, 2013; VAN LOMMEL, 2013).

Apesar de toda sua popularidade filosófica e relevância para o problema mente-cérebro, a pesquisa teórica/filosófica em âmbito nacional especificamente sobre o Fisicalismo é bastante incipiente, existindo somente um trabalho em português dedicado a revisar questões sobre a tese fisicalista (ZILIO, 2010) e nenhuma revisão conceitual sistemática sobre a definição do 'físico' nas teses fisicalistas. Portanto, o objetivo do presente trabalho é, a partir do recorte temático de um problema filosófico específico, a saber, a tese fisicalista e as definições do termo 'físico' pressupostas, realizar uma revisão das definições do 'físico' contidas nas teses fisicalistas dentro do debate contemporâneo em Filosofia da Mente, analisando suas implicações e consequências lógicas para o problema mentecérebro. O nível de análise da pesquisa é puramente teórico-semântico, identificando a definição do 'físico' nas principais posições fisicalistas sustentadas atualmente no campo de discussão da Filosofia da Mente. Nossa metodologia consiste em uma investigação teórico-filosófica de clarificação com base em revisão bibliográfica e análise lógica e conceitual.

\section{FISICALISMO: O MATERIALISMO ONTOLÓGICO CONIEMPORÂNEO}

Mas, afinal, o que é o Fisicalismo? O termo 'fisicalismo' começa a ser utilizado na Filosofia na década de 1930 com as publicações dos positivistas lógicos Rudolf Carnap (1891-1970) e Otto Neurath (1882-1945) (CARNAP, 1959; NEURATH, 1931a, 1931b). A tese geral, ressalvando as particularidades em cada autor, é a de que qualquer proposição dotada de sentido é passível de ser traduzida, sem perda de significado, em afirmações utilizando uma linguagem física (daí o termo 'Fisicalismo'). É, portanto, uma tese linguística/metodológica (e não ontológica) relacionada a uma concepção unificada da ciência via critérios de verificação intersubjetivos da linguagem observacional (FEIGL, 1963), sem pretensões - ao menos explícitas - de fazer alegações de ordem metafísica. O Fisicalismo, na forma como concebido por Carnap e Neurath, porém, não permaneceu hegemônico. Autores como Quine (1954) e Smart (1963, 1981) contribuíram na propagação da ideia de que a tese fisicalista era de natureza metafísica e não linguística. Alguns têm deixado claro o fato do fisicalismo contemporâneo não ser mais entendido como uma doutrina metodológica, mas sim ontológica (PAPINEAU, 2001). Há resistentes ao uso intercambiável dos termos 'fisicalismo' e 'materialismo' para descrever concomitantemente a posição filosófica de que tudo o que existe é fisicamente constituído (BUNGE, 2010), embora muitos autores não utilizem mais o termo 'materialismo' nas discussões ontológicas, somente 'fisicalismo' (STOLJAR, 2010).

Independentemente de questões terminológicas e da discussão sobre sua associação com o materialismo, na forma como vem sendo compreendido atualmente, o termo 'fisicalismo' genericamente representa a proposição de que todas as coisas existentes são físicas, não existindo nada além do físico (STOLJAR, 
2010). Considera, portanto, todos os processos ditos mentais submetidos a essa condição, seja por uma relação de identidade, seja por superveniência ou qualquer outro tipo de relação derivativa de bases fundamentalmente físicas. A partir da ideia fisicalista geral, diferentes distinções em suas modalidades e sentidos podem ser traçadas. Armstrong (1997) faz uma diferenciação entre duas versões, um fisicalismo forte e um fisicalismo fraco, tendo em vista a abrangência e a força das proposições. Nagel (1965) o divide em quatro tipos de formulações possíveis, desde uma afirmação de identidade específica entre condições mentais e sua contrapartida física, até versões mais brandas nas quais a identidade entre o físico e o mental é completamente flexibilizada. Fisicalistas contemporâneos reconhecem a possibilidade de expressão da "intuição geral" em múltiplos formatos, através da noção de redução, eliminação, superveniência física, realização física, identidade e assim por diante.

À primeira vista poderíamos pensar ser a popularidade do fisicalismo e sua ampla adesão consequência de um consenso oriundo de uma adequada formulação filosófica da tese. Entretanto, analisando mais de perto fatalmente somos confrontados com um panorama bastante diverso. $\mathrm{Na}$ realidade, pretendemos demonstrar ser mais aparente do que real o consenso em torno da proposição geral da tese fisicalista. Os filósofos têm apresentado diferentes definições gerais do que seria o fisicalismo (DOWELL, 2006b; FRANCESCOTTI, 2014; HELLMAN \& THOMPSON, 1977; JACKSON, 1998; KIM, 2005; PAPINEAU, 2001; POLAND, 1994; SCHIFFER, 1990; STRAWSON, 2006). Se o consenso tem girado em torno da ideia intuitiva de que fisicalismo é a tese responsável por alegar não existir nada para além do físico, por outro lado, dificuldades e discordâncias surgem com relação ao próximo passo, ou seja, como especificar cada componente presente nessa proposição geral. Pode-se dizer que os elementos comuns entre as formulações são (a) a proposição afirmativa generalizante ("Tudo é", "A totalidade", "Todos os fatos", "Todas as verdades", "Não há nada além") ancorada na (b) noção de físico ("Exaustivamente compostas por propriedades físicas"; "Fundamentalmente físico"; "É realizada por entidades físicas"; "Em última análise compostas por propriedades físicas"). Em contrapartida, são grandes as divergências entre as teses quanto ao que se quer dizer exatamente ao usar o operador lógico 'Tudo'/ 'Para todo' e, especialmente, o que o termo 'físico' designa.

\section{AS DISTINTAS FORMAS DE DEFINIR E CONCEBER O 'FÍSICO'}

Conforme brevemente descrito anteriormente, segundo o materialismo ontológico/fisicalismo ontológico, todas as classes dos fenômenos existentes seriam constituídas fisicamente, não existindo nada além. Mas, o que significaria dizer que tudo o que existe é "físico"? Como o termo 'físico' presente nas teses fisicalistas deve ser compreendido? Essa pergunta, conhecida como a Questão da Especificação (CROOK \& GILLET, 2001), tem rendido intensos debates nos últimos anos em um nicho restrito especializado em Filosofia.

Diante do problema da especificação do "físico" podemos, de um modo geral, identificar quatro categorias abrangentes nas tentativas de resposta à 
pergunta: (I) Definições de apelo à Física presente, também conhecidas por presentistas, que alegam ser físico somente o que a Física atual postula em seu sistema teórico como tal (HELLMAN \& THOMPSON, 1975, 1977; JACKSON, 1998, 2006; KIM, 2005; MELNYK, 1997, 2003; POLAND, 1994; SMART, 1978, 1981); (II) Definições de apelo à uma Física ideal, conhecidas por futuristas, cuja afirmação é de que físico é tudo aquilo contido numa compreensão completa do Universo de uma Física ideal do futuro (ARMSTRONG, 1997; DOWELL, 2006a; LOEWER, 2007; PETTIT, 1993); (III) Definição negativa, também conhecida como via negativa, a qual diz ser físico tudo aquilo que é não fundamentalmente mental (MONTERO \& PAPINEAU, 2005; SPURRETT \& PAPINEAU, 1999; WORLEY, 2006); e por fim, (IV) Definições híbridas e alternativas, composta pelos critérios de definição das opções anteriores combinados - por exemplo, uma definição futurista acrescida das restrições das definições negativas - e/ou restrições particulares para o que seria uma propriedade física (FEIGL, 1967; KIRK, 1996; MEEHL \& SELLARS, 1956; NIMTZ \& SCHUTTE, 2003; STOLJAR, 2001a, 2001b; VICENTE, 2011; WILSON, 2006; WITMER, 2016).

As definições de apelo à Física presente, ou definições presentistas do físico, geralmente identificam como físico todo o conjunto de entidades e propriedades fundamentais postuladas pela Física atual e/ou pela microfísica de partículas contemporânea. Portanto, estipular o que é o físico ou uma propriedade física nesta categoria de definição, ficaria a cargo da Física atual em seu sistema teóricoempírico. Podemos considerar autores como J. J. C. Smart, Hellman e Thompson, Jeffrey Poland, Andrew Melnyk, Frank Jackson e Jaegwon Kim como representantes dessa categoria conceitual.

J. J. C. Smart, forte representante do materialismo australiano, identifica a si mesmo como uma fisicalista, no sentido ontológico. Smart tornou-se famoso na Filosofia da mente por, em conjunto com U. T. Place, ter proposto, na década de 1950, a teoria da identidade mente e cérebro, alegando que cada estado mental particular é idêntico a um estado cerebral particular (SMART, 1959). Sua proposta consistia em defender o materialismo como uma teoria cuja reivindicação era de que não existe nada no mundo para além das entidades postuladas pela Física. Porém, em um primeiro momento, Smart fez uma observação disjuntiva relevante: o conteúdo fundamental da realidade, além do qual não existiria nada, poderia tanto ser as entidades determinadas como físicas pela Física atual, quanto as entidades que ainda viriam a ser postuladas no futuro por teorias físicas mais elaboradas (SMART, 1963, p. 651).

Em trabalhos posteriores, Smart (1978), buscando fornecer um conteúdo não disjuntivo e mais específico para seu fisicalismo, o definiu tendo por base somente a Física presente e atual, sem qualquer referência a entidades potencialmente postuladas por teorias físicas mais adequadas do futuro. O motivo oferecido pelo autor é que assim seria possível delimitar melhor o conteúdo do fisicalismo e, além disso, para os propósitos da Filosofia da biologia e da mente, seria suficiente e perfeitamente possível ancorar o fisicalismo aos princípios da Física presente. Posteriormente, Smart (1981) argumentou que sua posição seria um fisicalismo "não-definicional" e "não-dedutivo" (non-definitional and non- 
deductive physicalism). Novamente em sua última proposta, Smart reitera que ao definir o conteúdo de seu fisicalismo com relação ao problema mente-cérebro, identifica por 'físico' os conteúdos da Física atual e suas teorias.

Outro representante dessa estratégia de definição (com apelo à Física atual) é Frank Jackson. A forma como define as propriedades físicas vincula-se à capacidade da ciência, especialmente da Física, em conseguir designar um conteúdo para o termo 'físico'. Para clarificar o conceito central da tese, ou seja, delimitar o que seria uma propriedade física, o autor identifica três características distintivas: (a) não ser senciente; (b) ser amplamente similar ("broadly akin") àquelas postuladas pela Física atual; e (c) ser necessária para lidarmos com e explicarmos o nível micro da realidade (JACKSON, 1998, p. 08). Mais recentemente, Jackson (2006) reforçou a ideia de um fisicalismo a priori, insistindo na possibilidade de definir o físico, para os fins fisicalistas, de uma forma abrangente ancorado, enquanto tese metafísica, na Física e nas ciências físicas em geral, tais como a físico-química, a bioquímica. Nesse sentido, Jackson consiste em outro proponente da estratégia de definição através da ciência física contemporânea como forma de delimitar o físico do fisicalismo.

Por outro lado, as definições de apelo à Física futura ou definições futuristas são todas aquelas que, diferentemente da abordagem anterior, buscam identificar o físico tendo por base não as ciências físicas do presente, mas uma Física ideal do futuro, completa e verdadeira, capaz de fornecer uma teoria final da totalidade das coisas existentes no universo. De modo geral, tais definições são acompanhadas de um reconhecimento de que a Física atual ainda está incompleta, imprecisa, sendo necessário apelar para outra via no processo de especificação do 'físico'. O que seria exatamente tal Física ideal do futuro, completa e verdadeira? Embora não seja uma questão autoevidente, sendo explicitada somente por alguns, de modo geral, o que a maior parte dos representantes dessa abordagem considera enquanto tal é uma teoria epistemologicamente ideal e verdadeira, num cenário futuro, dentro dos limites máximos de aquisição do conhecimento, levando em conta todos os dados empíricos possíveis sobre os fundamentos últimos da realidade. Exemplos de autores que adotaram essa estratégia são Philip Pettit, David Armstrong, Janice Dowell e Barry Loewer.

A título de exemplo, vejamos a versão do fisicalismo, chamada de Microfisicalismo, apresentada por Pettit (1993). O autor considera central o compromisso com duas proposições gerais básicas: 1) O mundo empírico é constituído por entes que a Física está em melhor condição de identificar; e 2) O mundo empírico é governado por forças e regularidades que a Física está melhor equipada para descrever. Pettit descreve ainda quatro alegações adicionais, compostas por afirmações particulares, coerentes com as suas duas proposições centrais:

(I) Existem entidades microfísicas: (a) Existe um mundo empírico no formato daquele postulado pela Física; (b) Diferentes tipos de coisas no mundo empírico compartilham uma composição em seu nível subatômico no formato daquele postulado pela Microfísica - um domínio de minúsculas entidades microfísicas. 
(II) Entidades microfísicas constituem tudo o que existe: (a) Tudo no mundo empírico ou é composto, de algum modo, por entidades microfísicas postuladas pela Física ou não é composto, mas é um ente elementar em si; (b) Tal composição é conservadora, ou seja, duas entidades microfísicas não podem diferir intrinsecamente sem alguma diferença na configuração de seus componentes microfísicos.

(III) Existem regularidades microfísicas: (a) Entidades microfísicas estão submetidas a leis regulares em virtude de suas propriedades e relações microfísicas; (b) As leis operantes no domínio microfísico não são obtidas necessariamente por leis obtidas no nível macro. Podem ser leis iguais (conservação) ou diferentes, pois as leis microfísicas são primitivas.

(IV) As regularidades microfísicas governam tudo o que existe: (a) O nível macro não complementa as leis do nível micro; e (b) as leis macrofísicas não são independentes das leis do nível micro, ou seja, não têm o potencial de entrar em conflito com elas.

As quatro alegações supracitadas forneceriam suporte à ideia de que o mundo empírico contém somente o que uma Física verdadeira e completa afirmaria conter (PETTIT, 1993, p. 213). Apesar de sua formulação fisicalista deixar a cargo de uma Física completa designar o que é físico, assim como suas propriedades, Pettit (1993) estipula a existência de entidades microfísicas e determina restrições formais às relações de tais entidades com os demais domínios da realidade - uma Física completa e ideal descreveria o que são tais entidades microfísicas.

David Armstrong consiste noutro autor que podemos relacionar à abordagem que busca definir o físico através da ciência física ideal e completa. Armstrong, em seu $A$ World of states of affairs (1997), defende que tudo o que existe no espaço-tempo são entidades físicas governadas por leis físicas. Ao considerar que os únicos particulares contidos no sistema espaço-temporal são entidades físicas e, mais precisamente, as leis físicas de uma Física completa, Armstrong adota a estratégia de postular o físico ancorando-o numa Física ideal e completa: "It asserts that the only particulars that the spacetime system contains are physical entities governed by nothing more than the laws of physics. The thesis is to be understood as a thesis about a completed physics" (ARMSTRONG, 1997, p. 06).

Armstrong, em sua delimitação da tese combinada com seu naturalismo e factualismo, considera o fisicalismo passível de ser compreendido como a tese que afirma ou 1 ou 2:

(1) Todos os universais fundamentais, sejam propriedades ou relações, são aqueles estudados pela Física, e todos os outros universais de primeira ordem são estruturas que implicam nada além dos universais fundamentais.

(2) Todas as leis fundamentais são conexões entre os universais fundamentais e outras leis, as quais não são nada além do que as leis fundamentais operando sob condições específicas e fronteiriças. 
Embora apresente uma definição de natureza ontológica, o autor considera o fisicalismo um tipo de hipótese científica de alto nível, especulativa e reducionista. O fisicalismo, enquanto tese, extrairia sua autoridade da própria ciência - aqui restrita mais especificamente à Física.

Já no caso da definição negativa, também conhecida por via negativa, a proposta é definir o físico como tudo aquilo que é não mental, equacionando 'físico' com 'não mental' (MONTERO \& PAPINEAU, 2005; SPURRETT \& PAPINEAU, 1999). Alguns autores representativos dessa abordagem são David Papineau, David Spurrett, Barbara Montero e Sara Worley. Essa forma de definição é conhecida por via negativa justamente por buscar delimitar o físico através de uma definição do tipo negativa, ou seja, uma forma de definir algo por contraste com uma noção contrária.

David Papineau (1993; SPURRETT \& PAPINEAU, 1999) é um dos maiores representantes da resposta pela via negativa quando o assunto é tentar delimitar o que seria o 'físico' nas teses fisicalistas. Um dos famosos argumentos a favor do fisicalismo, o argumento causal da completude física (Completeness of Physics), é considerado uma base crucial em sua defesa de uma definição do físico por contraste negativamente com o mental. Formalizando mais especificamente o argumento da completude da Física sustentado pelo autor a favor do fisicalismo, temos:

(P1) Todos os efeitos físicos são completamente determinados por leis e ocorrências físicas anteriores.

(P2) Se P1 é verdadeiro (a completude da física) e todos os efeitos físicos são devidos a causas físicas, então tudo o que tenha efeito físico deve em si mesmo ser físico.

Logo, não existe espaço para qualquer coisa não física fazer diferença, em termos de efeitos causais físicos.

Mas o que seriam tais efeitos e ocorrências físicas? Spurrett e Papineau (1999) deixam clara sua posição quanto à definição do 'físico' ao defender que nenhuma especificação detalhada, seja a partir de uma Física ideal, completa e verdadeira do futuro ou até mesmo da Física atual, consiste em condição necessária para caracterizar a proposta fisicalista. A tarefa principal ao formular o fisicalismo, no entendimento dos autores, é muito mais de excluir categorias especiais (tais como fenômenos mentais para além do físico) do que do incluir. Garantir que o termo 'físico' não designe qualquer tipo de propriedades e eventos não físicos ou sobrenaturais já seria suficiente para satisfazer a condição necessária expressa pelo fisicalismo.

De forma semelhante, não considerando ser possível definir adequadamente o físico, seja fazendo referência à Física presente, seja a uma Física ideal do futuro, Montero (2011) adota como rota alternativa a definição negativa. Para capturar a ideia associada à tese ontológica fisicalista, a autora afirma ser possível definir o que são propriedades físicas através da delimitação dos tipos de 
propriedades que elas excluem. Isto é, as propriedades físicas seriam fundamentalmente não mentais, não divinas e não normativas, pois assim seria possível adequadamente fazer jus à inconsistência do fisicalismo com a existência de almas imateriais e propriedades mentais para além do domínio físico. O motivo apresentado, portanto, de uma adesão à via negativa seria o de que o ponto central de discordância entre fisicalistas e todos seus demais adversários no debate sobre a natureza da mente, em última instância, resume-se a questão da existência ou não de alguma característica especial e distintiva dos seres humanos no mundo natural (MONTERO, 2005).

Por fim, o que denominei de definições híbridas e alternativas consiste num conjunto mais recente de definições com características próprias, geralmente combinando aspectos das categorias gerais anteriores ou acrescentando elementos restritivos na especificação do físico não contidas nas categorizações anteriores. Desse modo, a categoria de definições híbridas e alternativas ou englobam definições que compartilham aspectos das categorias anteriores, porém, com novos elementos e/ou restrições, ou são totalmente distintas, idiossincráticas e alheias às abordagens anteriores. Autores passíveis de serem categorizados de tal forma são Meehl e Sellars, Herbert Feigl, Daniel Stoljar, Jessica Wilson, Robert Kirk, Agustín Vicente, Christian Nimtz e Michael Schütte, Witmer, dentre outros.

Um exemplo de tais definições híbridas do físico é a proposta de Jessica Wilson (2006). Denominada de NFM (no fundamental mentality), a qual, como o nome sugere, consiste em adicionar a restrição de negação da fundamentalidade do mental na definição do físico enquanto apela para a Física fundamental do futuro em sua definição. Sua proposta de definição pode ser formalizada da seguinte forma:

Def. Físico (No fundamental mentality, NFM): Uma entidade é física se, e somente se, satisfazer as seguintes condições:

I. É considerada como tal por uma Física fundamental do futuro; e

II. É fundamentalmente não mental.

O aspecto distintivo dessa estratégia é sua mescla de um apelo à Física futura com um critério restritivo do componente definicional central do fisicalismo. Combinando o apelo para a Física fundamental ideal como a ciência responsável por definir o que seja o 'físico' do fisicalismo, com tal restrição, a autora sustenta ser possível oferecer uma formalização mais adequada da tese. A relevância de adicionar a restrição de não fundamentalidade do mental visa evitar que o fisicalismo, pautando sua definição do físico numa Física do futuro, deixe em aberto a possibilidade para que essa mesma Física possa postular entidades e propriedades proto-fenomenais (mentais) enquanto fundamentais. Tal adição, segundo a autora, preservaria o fisicalismo enquanto tese antidualista de acordo com a tradição materialista, delimitaria seu conteúdo e garantiria a confiança geral 
atribuída à Física como responsável por melhor identificar as entidades fundamentais da realidade.

De forma semelhante, Robert Kirk (1996) descreve por 'físico' o que quer que a Física postule enquanto tal, ao mesmo tempo em que busca excluir todas as expressões que podem ser consideradas psicológicas ou mentais. Recentemente, reforçando tal posição, e sem maiores delongas com relação à tarefa de definição do físico, Kirk (2013) afirma compreender o termo 'físico' de acordo com uma Física verdadeira e idealizada ('imagined true physics'), a qual não invoca fundamentalmente a consciência, intencionalidade ou qualquer outra noção psicológica na descrição e explicação das bases fundamentais do ser humano e demais organismos.

Nossa categorização ocorre não tendo como escopo esgotar todas as possibilidades de distinção e sistematização do conceito, mas somente de revisar panoramicamente como ele vem sendo discutido na Filosofia da Mente contemporânea, fornecendo assim, subsídios para uma análise mais acurada e derivações lógicas mais restritas. Em cada uma dessas categorias proliferam tentativas e propostas específicas de delimitação das condições necessárias para uma definição adequada do que venha a ser o "físico" presente nas teses fisicalistas. Apesar dos esforços, a questão da definição do termo 'físico' tem se evidenciado um problema filosófico de difícil solução.

Dentre as principais críticas ao problema da especificação encontramos a objeção da circularidade, o Dilema de Hempel, a crítica de Chomsky, de Bas Van Fraassen e de Chris Daly/ Israel Scheffler. A seguir iremos brevemente descrever algumas das críticas centrais aos esforços de delimitação do físico na formulação do fisicalismo contemporâneo.

\section{OBJEÇÕES E OBSTÁCULOS À DEFINIÇÃO DO 'FÍSICO'}

Inicialmente, podemos pensar existir muitas opções, nessa miríade de definições, capazes de serem integradas à tese fisicalista e sua defesa da primazia do físico sobre o mental no debate mente-cérebro. Apesar de tais esforços, a pergunta "O que é o físico?" é bastante problemática e de difícil resposta.

O problema da circularidade (STOLJAR, 2010, 2016) consiste na imputação de circularidade na especificação das propriedades físicas em algumas definições, ou seja, ao tentar explicitar o que seria uma propriedade física invocando uma outra noção também considerada física (um objeto físico ou uma teoria sobre o que é físico), a caracterização do físico seria circular. A circularidade ocorre quando em uma definição de um termo X o conteúdo designado previamente já pressupõe

$\mathrm{X}$, ou seja, aquilo que busca definir. Em outras palavras, é um tipo de definição incapaz de esclarecer o que deseja definir, pois acaba por incluir na definição o termo a ser definido. Portanto, uma definição circular possui em seu definiens o próprio definiendum. Por exemplo, imaginemos uma proposta cujo objetivo seja definir o 'físico' através da seguinte definição: 
Def. Físico: Tudo aquilo que em nosso discurso natural denominamos como objeto físico.

O exemplo, embora exageradamente grosseiro, ajuda a traduzir com mais clareza um tipo de definição circular, bem como tornar evidente o problema lógico enfrentado por esse tipo de definição. Em muitos casos, uma definição pode ser circular de forma mais tácita, quando apela para termos correlatos ou sinônimos daquele a ser definido. Portanto, a crítica de circularidade na definição do 'físico', nesse sentido, se aplicaria a qualquer definição que faz o uso, implícito ou explícito, de noções já pressupostas como físicas na definição do próprio físico. Esse tipo de definição não seria apropriado, à medida em que não delimita e estipula um predicado específico capaz de caracterizar aquilo que seria o conteúdo central da tese fisicalista.

Outra objeção, o Dilema de Hempel (HEMPEL, 1969; 1980), amplamente citado na discussão em torno do problema da especificação, seja como crítica, seja como obstáculo a ser superado, pode ser sintetizado da seguinte forma: Se o conceito de físico for baseado na Física contemporânea, o fisicalismo provavelmente é falso, porque as noções de físico têm sofrido historicamente significativas alterações e não existem razões para acreditarmos ser a Física atual uma descrição fiel e completa da realidade, muito pelo contrário. Por outro lado, se a noção de físico for ancorada numa Física ideal, uma Física futura completa, por consequência, seu conteúdo se torna obscuro e vago na medida em que seria impossível predizê-lo. Além disso, soma-se a essa última parte do dilema o que ficou conhecido como o problema do pampsiquismo (STOLJAR, 2016). Apenas apelar na definição de físico para propriedades e objetos paradigmaticamente físicos, não inclui nenhuma referência ontológica sobre os mesmos, assim, deixa em aberto a possibilidade de uma Física completa e ideal do futuro chegar à conclusão de que propriedades mentais fazem parte da natureza fundamental da realidade. Caso esse cenário hipotético aconteça, a Física estaria propondo a tese pampsiquista e/ou suas variações, o que levanta a questão se seria possível o fisicalismo na forma como é entendido hoje ser compatível ou não com a existência de propriedades mentais fundamentais e irredutíveis. Nesse caso, o problema é que tradicionalmente o pampsiquismo é uma tese antagônica ao materialismo ontológico, ou seja, definir o físico de modo que a proposição materialista seja compatível ou afirme a tese pampsiquista consistiria justamente numa tese não fisicalista, por definição, não sendo uma alternativa enquanto critério de definição capaz de delimitar as condições mínimas para uma tese fisicalita.

As observações de Hempel tiveram como resultado uma série de controvérsias quanto à adequabilidade da definição do físico e ainda hoje são motivo de acirradas disputas teóricas. Consiste numa crítica que obteve um amplo alcance, sendo reconhecida, seja por detratores, seja por defensores do fisicalismo (CRANE \& MELLOR, 1990; HELLMAN, 1985; MONTERO, 2005; POLAND, 1994) como um problema sério a ser evitado ou superado nas definições do físico.

A crítica de Chomsky $(1972,1994)$ sinaliza dois aspectos problemáticos nas tentativas de formulação de um conceito do físico, a saber, a trivialidade da tese 
fisicalista e a sua vagueza conceitual. O primeiro componente de sua crítica consistiria justamente, de certo modo, no problema lógico de a tese ser trivialmente verdadeira em função da forma com o físico é definido. Seu conteúdo seria maleavelmente adaptado aos avanços da atividade científica, sempre aberto a revisão, ou seja, qualquer reformulação da noção de físico postulada pela Física seria integrada, como já foi em outros momentos da história da ciência, ao framework fisicalista a partir de uma revisão do conceito, tornando o fisicalismo trivialmente verdadeiro.

Chomsky destaca, além do problema da trivialidade, o problema da vagueza, ou seja, o fato de conceitos como "físico" e "material", pressupostos em toda discussão sobre a natureza do mental, serem desprovidos de um sentido claro. Evidentemente, a vagueza em torno dos termos 'mental' e 'físico', por consequência, favoreceria justamente o materialismo usar o termo 'físico' para acomodar qualquer fenômeno, reforçando a possibilidade de a tese fisicalista ser trivialmente verdadeira. Afirmar, por exemplo, que tudo o que existe é físico, pressupondo que tudo o que a Física irá identificar quando estiver completa será físico, consistiria numa tese trivialmente verdadeira. Sua conclusão é de que na ausência de clareza quanto à definição e distinção do conteúdo de tais termos, aparentemente não seria possível a existência de qualquer proposta materialista, em seu sentido ontológico, e até mesmo do próprio problema mente-cérebro.

A crítica de Van Fraassen (1996) compartilha aspectos das anteriores e possui como eixos centrais: (a) a indeterminação do conteúdo da tese fisicalista; (b) a impossibilidade de falseamento; e (c) a defesa do argumento de que o fisicalismo não é uma hipótese científica, nem sequer uma tese filosófica, mas sim uma atitude. Fraassen considera terem fracassado as tentativas de resolver o problema da falta de conteúdo e clareza da tese, não conseguindo fornecer substancialidade ao fisicalismo. Segundo o próprio autor, o fisicalismo adotaria uma crença na veracidade de um "não sei o quê" baseada em um otimismo corajoso. Essa indeterminação do conteúdo, por seu turno, estaria diretamente relacionada à impossibilidade de falseamento da tese, pois uma vez que se compatibiliza sempre o significado de físico com os achados da Física mais atual, seja o que for por ela postulado, os novos dados empíricos nunca seriam capazes de contradizer a tese.

Segundo o autor, o materialismo seria uma tradição filosófica com uma roupagem diferente em cada era, com suas próprias reivindicações empíricas e teóricas, mantendo um núcleo de atitude e convicção invariante, ao qual Fraassen denomina de "o espírito do materialismo". Independentemente da tese, seu formato, termos e definições adotadas, o materialismo em cada época permaneceria sempre sobrevivendo, adaptando e se reinventando. Ou seja, embora os fisicalistas acreditem estar sustentando uma tese ontológica ou hipótese científica, na realidade, estariam expressando uma atitude sustentada em confusas condições desprovidas de maior clareza conceitual.

Em poucas palavras, não existiria, na forma como a tese vem sendo formulada, critérios adequados de verificação de sua falsidade. Existiria sempre a possibilidade de, mediante a ausência de evidências favoráveis, surgir uma nova versão da tese ou um enfraquecimento da mesma para acomodar os dados 
empíricos produzidos pela atividade científica e, portanto, afirmações empíricas específicas não seriam capazes de desacreditá-la completamente. Por fim, Fraassen considera que o materialismo (entendido como sinônimo de fisicalismo ontológico) não pode ser considerado uma tese, mas sim um conjunto de atitudes, uma tradição filosófica, a qual em cada época da história tem desenvolvido a capacidade de ajustar seu conteúdo, recuar nas alegações e se remodelar como proposta filosófica. Esse seria o "espírito filosófico materialista", uma atitude filosófica e não uma tese.

As críticas de Chris Daly (1998) e Israel Scheffler (1950) caracterizam-se pela afirmação de que até a presente data não existe nenhuma distinção, baseada em princípios claros e bem definidos, entre o que seja uma propriedade física contrastante com as demais propriedades existentes, tendo com isso, duas implicações: (a) o fisicalismo não é uma tese bem definida, e (b) o debate entre o fisicalismo e dualismo, especificamente sobre o valor de verdade das teses, não faz sentido mediante a falta de clareza de um conceito fundamental presente na formulação de ambas.

Chris Daly (1998), ao investigar dentro dos domínios da metafísica das propriedades a seguinte questão "O que são propriedades físicas?", deriva uma conclusão bastante similar à de Scheffler por uma linha argumentativa diferente. Israel Scheffler, em seu trabalho de 1950, The New dualism: Psychological and Physical terms, analisa e faz críticas à distinção pressuposta entre as noções atribuídas aos termos 'psicológico' e 'físico', tendo por base os principais membros do círculo de Viena. A consideração de Scheffler é de que as tentativas dos positivistas lógicos, por ele analisados, de traçar uma linha divisória clara entre os termos 'físico' e 'psicológico' não foi capaz de obter sucesso. E de forma mais pungente, conclui não apenas que todas elas eram inadequadas, mas também que os esforços nessa direção eram inúteis. Já Daly, mais recentemente, buscou identificar quais são as bases de distinção - seus princípios, critérios de classificação, delimitação - pressupostas por algumas das principais abordagens ontológicas na diferenciação da classe de propriedades físicas com relação às demais propriedades existentes. Ao avaliar o status das principais abordagens - na atualidade - que visam estabelecer tais distinções (a saber, a proposta de Geoffrey Hellman, Poland, Papineau, Armstrong, bem como as definições de apelo à física atual e a uma Física ideal, completa e verdadeira do futuro) argumenta serem todas elas insatisfatórias. Ao analisar o problema de como distinguir a classe de propriedades físicas contingentes das demais, argumenta que tal fronteira não pode ser traçada, fazendo referência às propriedades existentes no mundo real, pois ainda que seja o caso de todas as propriedades do mundo real serem físicas, ainda seria necessário saber: (a) o que torna uma propriedade, uma propriedade física; e (b) dentre as propriedades possíveis, o que faz com que algumas delas sejam físicas e outras não. Sendo assim, o fisicalismo precisaria oferecer uma distinção, dentre todas as propriedades reais e possíveis existentes no universo, de quais seriam propriedades físicas, assim como sob os mesmos aspectos, quais não seriam.

Após sua minuciosa análise das principais abordagens existentes candidatas a estipular uma distinção entre uma propriedade física e as demais, sua conclusão, 
portanto, é a de que não existe ainda nenhuma noção clara e bem definida do que seja uma propriedade física. Além disso, o autor levanta a questão se realmente existiria um princípio de distinção entre propriedades físicas e as demais existentes na natureza. A conclusão de Daly é imediata e pontual: não existiria nenhum princípio e critério de distinção bem definido entre o que seria uma propriedade física capaz de diferenciá-la de qualquer outra propriedade. Por consequência, considera intratável a questão da distinção do que seja uma propriedade física, chegando a afirmar, por fim, a necessidade de abandono dos programas metafísicos que pressupõe tal distinção. Como consequência, pressupor a existência de tal distinção é um equívoco, a noção de propriedade física não estaria bem definida inexistindo explicações satisfatórias do que ela seja até o presente momento. Tais problemas de ordem conceitual na formulação da noção de físico dissolveriam o problema mente-cérebro.

Além dos autores supracitados, outros têm reforçado as fileiras de críticas ao fisicalismo, enfatizando a ausência de uma divisão evidente entre o mental e não mental, a falta de uma noção clara do que seja um objeto/propriedade físico ou a trivialidade lógica em algumas versões do fisicalismo. Objeções e dificuldades com relação às tentativas específicas de definição e solução do problema também foram identificadas (CRANE \& MELLOR, 1990; FRANCESCOTTI, 2014; SCHAFFER, 2003; STURGEON, 1998). Diferentes iniciativas de superação das críticas acima mencionadas e apresentação de uma definição final do físico têm sido evidenciadas na literatura, assim como movimentos de fortalecimento das críticas já existentes (BISHOP, 2006; BLUMSON \& TANG, 2015; BOKULICH, 2011; DOWELL, 2006a; GILLETT \& WITMER, 2001; HELLMAN \& THOMPSON, 1975; JUDISCH, 2008; MELNYK, 1997, 2001, 2003; MONTERO, 2005; MONTERO \& PAPINEAU, 2005; MSIMANG, 2015; NEY, 2008; PAPINEAU, 1991; POLAND, 2003; SMART, 1978; SPURRETT, 2001, 2015; STOLJAR, 2010, 2001a, 2001b). Contudo, o fato de ainda ser possível identificar nas últimas décadas diferentes produções buscando discutir e propor definições da tese fisicalista, bem como publicações recentes sugerindo uma "nova definição de físico" (WITMER, 2016) e do fisicalismo (DOVE, 2016), são evidências suficientes para demonstrar a ausência de consenso dos critérios definicionais, devido às discordâncias relativas àquilo que a proposição irá abarcar, restringir e denotar pelo termo 'físico'. Ademais, até a presente data não está claro o quanto e se tais objeções foram adequadamente respondidas e superadas.

\section{IMPASSES E IMPLICAÇÕES DERIVADAS DO PROBLEMA DA DEFINIÇÃO DO 'FíSICO'}

Tendo por base tudo o que foi apresentado até aqui, podemos estabelecer algumas considerações sobre o problema da definição do físico. Partindo de um predicado F - para o termo 'físico', temos:

(I) Se o predicado $\mathrm{F}$ faz referência a propriedades descritas pela Física contemporânea/atual, resulta em (a) predicações temporárias sujeitas a alterações, radicais ou parciais, com o desenvolvimento futuro da Física; e/ou (b) aumento da probabilidade da tese fisicalista ser falsa em sua formulação devido às limitações 
da Física atual; e/ou (c) numa definição inapropriada, incapaz de abarcar a extensão factual do conceito por ela designado;

(II) Se o predicado F faz referência a propriedades descritas por uma Física ideal, completa e verdadeira no futuro, resulta em (a) vagueza conceitual; e/ou (b) trivialidade lógica da tese fisicalista; e/ou (c) possibilidade de, em última instância, dependendo do que uma teoria final da Física identificar, transformar-se num pampsiquismo ou ser identificada com demais teses rivais;

(III) $\mathrm{Se} O$ predicado $\mathrm{F}$ identifica o físico negativamente enquanto propriedade 'não mental' resulta em (a) não definir de forma clara e positiva o que é o mental; e/ou (b) na incapacidade de excluir teses rivais, devido a sua potencial compatibilidade com a noção de elán vital, o que não seria nem físico, nem mental, por exemplo (STOLJAR, 2016); e/ou (c) numa definição excessivamente restritiva com relação a algumas propriedades tidas como existentes enquanto 'não físicas' (numerais, valores, etc.); e/ou (d) num deslocamento de alguns obstáculos da definição do 'físico' para outras áreas, como o caso da Fisiologia e Neurofisiologia, ao buscar definir e explicar o mental; e/ou (e) numa definição que implica na falsidade de teses rivais, excluindo-as do debate sobre seu valor de verdade, antes mesmo de ele começar por mera estipulação definicional ( como é o caso do pampsiquismo, excluído a priori do debate mente-cérebro pela definição negativa);

(IV) Se o predicado F faz referência, explícita (dimensão física, dimensão temporal, dimensão espacial, partículas físicas, objeto físico, processos biológicos, orgânicos etc.), ou implícita (objetos paradigmaticamente considerados como físicos, objetos macro perceptíveis sensorialmente etc.) a elementos já pressupostos como presentes na propriedade (físico) que necessita ser esclarecida, implica (a) numa definição circular - definir físico como 'dimensão física' ou 'objetos paradigmaticamente considerados físicos' pressupõe aquilo que justamente precisa ser definido, ou (b) numa definição pouco informativa por ser definida de forma sinonímica; ou (c) numa incompatibilidade com as próprias descobertas da Física, tais como eventos existentes não categorizáveis em termos de localização espacial, partículas momentaneamente não identificáveis num momento tem nenhum lugar da rede espaço-temporal; ou (d) numa designação de noções novamente da Física, seja ela atual ou futura, tais como "espaço", "tempo", "rede espaço-temporal" e assim por diante, incorrendo nas mesmas limitações das condições (I) e (II).

Até a presente data não existe nenhum consenso sobre quais condições são necessárias e suficientes para adequadamente obtermos uma definição do físico não trivial, não analiticamente verdadeira, não desprovida de conteúdo e passível de permitir o fisicalismo ser uma tese falseável. Qual a relevância de tudo isso? Quais são, então, as implicações lógicas desse problema conceitual para o debate mente-cérebro?

Em primeiro lugar, o fato de que essa questão não consiste meramente de uma disputa terminológica, mas de uma verdadeira questão filosófica. As divergências vão desde quais seriam os critérios apropriados para designação do conceito e tradução do seu conteúdo até se as diferentes categorias de definição 
(negativa, positiva, indexadoras etc.) seriam suficientes, não somente para definir o 'físico', ao menos de acordo com uma condição mínima em particular, mas também para superar as severas objeções e obstáculos suscitados pelo problema. O problema do físico, em especial, parece inexoravelmente estar relacionado a outros tópicos de discussão filosófica mais complexos, a saber, a natureza das definições, a natureza das propriedades e relações, assim como a natureza e caracterização dos objetos existentes na realidade. Tradicionais questões e discussões filosóficas estão, implicitamente, associadas ao nosso objeto de investigação, tendo, tal relação, sido negligenciada pelos seus proponentes.

Em segundo lugar, está razoavelmente claro que as diferentes categorias de definição, assim como as diversas condições estipuladas como necessárias pelos fisicalistas para a definição do 'físico' (algumas compatíveis entre si, outras não coextensivas e, por fim, outras incompatíveis) quando contrastadas, indicam no estágio atual de investigação, uma ausência de critério claro quanto à questão, bem como o que venha ser uma formulação adequada do fisicalismo. Se boa parte das críticas forem verdadeiras, a noção de físico seria conceitualmente desprovida de conteúdo, um "vale qualquer coisa" se tiver credenciais científicas. Como consequência, qualquer evento, objeto, estado e/ou propriedade poderia ser categorizada como "físico", desde entidades teorizadas pela Física no presente como desprovidas de massa e de localização espacial determinada até cordas unidimensionais. Logo, não só o fisicalismo seria infalseável, como também trivialmente verdadeiro na ausência de restrições e no estabelecimento de condições mais específicas para a noção de físico. Alguns fisicalistas denominaram de "o problema do corpo" esse difícil obstáculo teórico no contexto da discussão mente-cérebro (MONTERO, 1999).

Em terceiro lugar, o reconhecimento de que o problema da designação do físico implica na própria inexistência de uma tese capaz de ser analisada quanto ao seu valor de verdade. Com efeito, se não temos uma clara definição do 'físico', não temos sequer uma tese fisicalista. E se não temos uma tese fisicalista, a discussão sobre o valor de verdade da tese se torna infrutífera, assim como qualquer tentativa de falseamento da mesma através de evidências empíricas. E levando as derivações ao extremo, como faz Daly, nem mesmo existiria um debate dualismo e fisicalismo, um problema mente-cérebro, caso ambas as teses não consigam lidar com os problemas de definição básicos inerentes às suas caracterizações filosóficas. Corremos o risco, assim, de estarmos discutindo predileções, atitudes, não enunciados e posições filosóficas, conforme já foi sinalizado.

Em quarto lugar, um aprofundamento na análise das diferentes versões fisicalistas, no que se refere às relações por elas estipuladas entre o macrofísico e o microfísico (explicitação da causalidade entre as diferentes ordens dos fenômenos, relações entre propriedades físicas fundamentais e as propriedades mentais, dentre outros), se fazem ainda hoje necessárias. Inclusive, tal problema é investigado, discutido e carente de respostas finais na própria Física contemporânea (BOKULICH, 2008). A análise neste domínio teórico evidentemente não dissociada do problema conceitual - é crucial no sentido de 
evitar a criação indireta de outras aporias, tais como as que têm sido observadas em explicações neurocientíficas atribuindo propriedades psicológicas a áreas cerebrais, estruturas neurofisiológicas de massa encefálica. Tal equívoco em atribuir predicados ao cérebro dotados de sentido somente quando utilizados para referenciar um indivíduo em sua totalidade, uma pessoa, consiste na falácia mereológica (BENNETT \& HACKER, 2003). Infelizmente, afirmações do tipo "o cérebro percebe", "um conjunto de neurônios decidiram disparar", dentre tantas outras são mais comuns do que se possa imaginar no campo especializado. Sem perceber, podemos em lugar do fantasma da máquina de Ryle (1949) criar "fantasmas da massa" em tais equívocos lógicos e conceituais. A descrição e exploração específica da relação entre o domínio macro e microfísico são questões estritamente vinculadas ao problema conceitual aqui apresentado, igualmente relevante e de grande impacto nas discussões sobre o problema mente-cérebro.

A presente conjuntura de definições gerais de fisicalismo incompatíveis entre si, propostas divergentes de definições do termo 'físico' utilizadas nas teses, desacordo sobre os critérios de adequação e as condições necessárias para formulação do conceito e a existência de notáveis desafios teóricos como as críticas apresentadas já são suficientes, acredito, para nos fazerem pensar: Por que estamos discutindo no mainstream da Filosofia da Mente o valor de verdade de uma tese que nem mesmo tem conseguido ser formulada de forma adequada? Se não conseguimos definir nem o que é um objeto ou uma propriedade física, não faria sentido perguntar se tal coisa é igual ou diferente de um objeto ou uma propriedade dita mental.

O que estou argumentando é que, na ausência de uma definição do termo 'físico', não é possível existir uma tese geral do fisicalismo, mesmo em meio à também vaga intuição de que a tese deveria afirmar ser tudo o que existe físico, uma vez que dependendo da sua designação, a tese automaticamente pode se transformar em qualquer coisa, inclusive num pampsiquismo, ou numa variação do idealismo. Defendo, portanto, que não temos prestado a devida atenção num passo anterior ao debate mente-cérebro, ou seja, o sério problema da especificação do 'físico', sem a resolução do qual não temos debates concretos à mesa. Em termos comparativos, embora venha sendo discutido nos últimos anos, a questão ainda está num segundo plano em relação a outros tópicos amplamente debatidos em Filosofia da Mente. E na melhor das hipóteses, caso seja possível existir o debate na ausência da própria tese, nossas análises e discussões em nichos específicos circundantes ao problema mente-cérebro têm sido feitas ancoradas em falsas pressuposições de consenso e clareza conceitual. Portanto é imperativo que se busque uma resposta a essa questão antes de dar continuidade a discussões sobre o valor de verdade das divergentes alternativas filosóficas apresentadas como soluções ao problema mente-cérebro.

Igualmente, acredito que a busca por soluções não pode perder de vista alguns questionamentos: Seria essa multiplicidade de teses e definições de físico um sintoma a evidenciar que talvez a ideia, a noção por detrás desse conceito, seja tão difícil de traduzir em palavras quanto os qualia? Ou uma mera disputa de preferências teóricas? Seria possível defender a tese fisicalista na ausência de uma definição clara e consensual de 'físico'? Poderia nosso Zeitgeist filosófico estar 
equivocado e estar seguindo implicitamente, de forma um tanto quanto acrítica, influências históricas atreladas a um otimismo cientificista? O fato é que não existe uma definição de físico amplamente aceita que não enfrente minimamente uma série de dificuldades teóricas. E isso é um problema tanto para o fisicalista, quanto para o dualista.

\section{CONSIDERAÇÕES FINAIS}

Nossa pesquisa chama atenção para um problema que, embora venha crescentemente sendo reconhecido e analisado por muitos autores, ainda é pouco explorado, de modo geral, nas discussões em torno da natureza da mente humana e do problema mente-cérebro. Consiste numa revisão sistemática sobre o problema da definição do físico na formulação da tese fisicalista, algo até então inexistente no contexto filosófico brasileiro dado à ausência de publicações específicas sobre esse tópico de investigação. Por fim, apresentamos igualmente os obstáculos e aporias envolvidos nesta empreitada teórica, bem como nossa análise lógicaconceitual das implicações para o fisicalismo e o problema mente-cérebro.

É importante reconhecer, igualmente, o fato de que qualquer proposta de definição, de delimitação conceitual da noção de físico pautada na pergunta "O que é o físico no Fisicalismo?", invariavelmente, estará já respondendo implicitamente questões filosóficas basilares e outras, não abordadas anteriormente. Algumas delas são: (a) É possível conhecer aquilo que o termo 'físico' tem como objetivo designar?; (b) É possível definir a noção de 'físico', em termos linguísticos, sem qualquer prejuízo lógico ou distorção do seu definiens?; (c) É possível, ao sermos portadores (ainda que em termos cognitivos de primeira pessoa) de uma noção clara da fisicalidade do mundo, sermos capazes de descrevê-lo linguisticamente de forma que possa ser algo intersubjetivamente checável e dotado de um sentido compartilhado?; (d) Pressupondo que existem propriedades no mundo, é possível distinguir propriedades físicas, minimamente, das demais?; e assim por diante.

Tendo isso em vista, sem uma clara definição conceitual, acreditamos ser improvável emergir qualquer resposta definitiva ou solução no nível do valor de verdade das teses. Na ausência de uma formalização clara, da tese fisicalista e de seu conceito central, estamos debatendo em dois níveis: um lógico-empírico, na medida em que se listam argumentos e evidências empíricas a favor e contra; outro conceitual, onde se pressupõem noções intuitivas, porém, mal definidas, de tais propostas. Portanto, argumentamos ser necessário dar um passo atrás na busca pela solução, se existente, para o problema mente-cérebro. Esse passo só pode ser dado tratando e considerando seriamente o problema da definição do físico, bem como todos os problemas ainda mais básicos de Filosofia da Linguagem e da relação entre conceitos e o mundo empírico implicados na questão.

Kim (2005) está parcialmente correto ao afirmar que os esforços atuais em Filosofia da Mente têm sido direcionados predominantemente em como reduzir a mente à dimensão física. Em especial, na busca de encontrar o lugar do "mental" no mundo natural. E o problema é justamente esse. Sustento que esse tipo de 
discussão só faz sentido quando temos alguma clareza do que seria essa "base" a qual é reduzida ou vinculada a natureza do mental. Reduzir, ancorar ou vincular, seja por qual tipo de relação for, os fenômenos mentais a um outro domínio, a saber, a dimensão física, cerebral, só faz sentido quando se sabe o que ela é - e do ponto de vista lógico-filosófico, quando se consegue definir sobre o que se está exatamente falando. Talvez esse seja o real "hard problem" da Filosofia da Mente em torno do problema mente-cérebro. Existe um abismo entre o sentido psicológico que automaticamente, cognitivamente, atribuímos ao termo 'físico' e suas diversas acepções e possibilidades de definições, o que favorece a conclusão de que estamos diante de um problema filosófico quando na realidade sequer começamos a compreendê-lo adequadamente. Significar psicologicamente um termo é algo completamente diferente de designar, de forma lógica e mais rigorosa, o conteúdo de uma proposição filosófica.

Ao considerarmos a disputa no nível empírico quanto à natureza do mental, a relevância do nosso objeto de investigação novamente se apresenta como imediata. Dados empíricos não dizem nada por si só, mas precisam ser interpretados. Quanto menos específico e claro é o framework teórico-conceitual, maior a probabilidade de qualquer dado ser identificado como evidência favorável por análises post hoc e estratégias ad hoc. Uma consequência indesejada que antevemos disso tudo é que o debate se torna uma eterna busca por evidências de ambos os lados, sem maior conclusividade, "vencendo" os defensores que tiverem maior poder de influência e persuasão em todas as variáveis de natureza não lógica e não racional (sociais, culturais e econômicas) relacionadas à pesquisa, seja ela filosófica, seja ela científica.

O fato é que não existe uma definição de físico amplamente aceita que não enfrente minimamente uma série considerável de robustas dificuldades teóricas. E de nada adianta uma tese ter influência nos meios acadêmicos se não tem substância filosófica. A temerosa pergunta levantada por Colin McGinn no título de seu artigo "Será que podemos resolver o problema mente e corpo?" remete-nos a Kant em seu primeiro prefácio da Crítica: "A razão humana, num determinado domínio dos seus conhecimentos, possui o singular destino de se ver atormentada por questões, que não pode evitar, pois lhe são impostas pela sua natureza, mas às quais também não pode dar resposta por ultrapassarem completamente as suas possibilidades". Sem embargo, não há razões para acreditarmos que a razão atormentada e insatisfeita deixará de continuar perenemente sua busca por respostas, mesmo sem garantia da possibilidade de factualmente obtê-las.

\section{REFERÊNCIAS}

ARMSTRONG, David M. A materialist theory of the mind: Revised edition. London: Routledge, 1993.

A World of states of affairs. Cambridge: Cambridge University Press, 1997. 
BEAUREGARD, Mario et al. Manifesto for a post-materialist science. Explore, v. 10, n. 5, p. 272-274. 2014.

BENNETT, Max; HACKER, Peter. Philosophical foundations of neuroscience. New Jersey: Wiley-Blackwell, 2003.

BISHOP, Robert. The hidden premise in the causal argument for physicalism. Analysis, v. 66, p. 44-52, 2006.

BLUMSON, Bem; TANG, Weng. A note on the definition of physicalism. Thought, V. 4, p. 10-18, 2015.

BOKULICH, Alisa. Reexamining the quantum-classical relation: beyond reductionism and pluralism. Cambridge: Cambridge University Press, 2008.

BOKULICH, Peter. Hempel's dilemma and domains of physics. Analysis, v. 7, n. 4, p. 646-651, 2011.

BOURGET, David; CHALMERS, David. What do philosophers believe? Philosophical Studies, v. 170, n. 3, p. 465-500, 2014.

BUNGE, Mario. Matter and mind: a philosophical inquiry. New York: Springer, 2010.

CARNAP, Rudolf. Psychology in physical language, In: AYER, Alfred (Ed.). Logical positivism. New York: The Free Press, 1959. p. 165-198.

CHALMERS, David J. Facing up to the problem of consciousness. Journal of Consciousness Studies, v. 2, n. 3, p. 200-219, 1995.

The conscious mind: in search of a fundamental theory. Oxford: Oxford University Pres, 1996.

Consciousness and its place in nature. In: STICH, Stephen; WARFIELD, Ted (Eds.). Blackwell guide to the philosophy of mind. Oxford: Blackwell, 2002. p.102-142.

CHOMSKY, Noam. Language and mind. New York: Harcourt, Brace, Jovanovich, 1972.

Naturalism and dualism in the study of language and mind. International Journal of Philosophical Studies, v. 2, n. 2, p. 181-209, 1994.

CHURCHLAND, Paul. Eliminative materialism and the propositional attitudes. Journal of Philosophy, v. 78, n. 2, p. 67-90, 1981.

CRANE, Tim; MELLOR, David. There is no question of physicalism. Mind, v. 394, p. 185-206, 1990.

CROOK, Seth; GILLETT, Carl. Why physics alone cannot define the 'physical': materialism, metaphysics, and the formulation of physicalism. Canandian Journal of Philosophy, v. 31, n. 3, p. 333-359, 2001.

DALY, Chris. What are physical properties? Pacific Philosophical Quarterly, v. 79, p. 196-217, 1998. 
DENNETT, Daniel. Kinds of minds: towards an understanding of consciousness. New York: Basic Books, 1996.

DOVE, Guy. Redefining Physicalism. Topoi, v. 37, n. 3, p. 513-522, 2016.

DOWELL, Janice L. The physical: empirical, not metaphysical. Philosophical Studies, v. 131, n. 1, p. 25-60, 2006 a.

Formulating the thesis of physicalism: An introduction. Philosophical Studies, v. 131, n. 1, p. 1-23. 2006b.

FEIGL, Herbert. Physicalism, unity of science and the foundations of psychology. In: COHEN, Robert S. (Ed.). Inquiries and provocations: Vienna Circle Collection, v. 14. New York: Springer, 1963. p. 302-341.

The "mental" and the "physical". Minneapolis: University of Minnesota Press, 1967.

FODOR, Jerry A. The mind-body problem. Scientific American, v. 244, p. 114-125, 1981.

FRANCESCOTTI, Robert. Physicalism and the mind. Dordrecht, Heidelberg, London, New York: Springer, 2014.

GILLET, Carl; LOEWER, Barry. Physicalism and its discontents. Cambridge: Cambridge University Press, 2001.

GILLETT, Carl; WITMER, D. Gene. A 'physical' need: physicalism and the via negativa. Analysis, v. 61, n. 272, p. 302-309, 2001.

GREYSON, Bruce. The implications of near death experience for a postmaterialist psychology. American Psychological Association, v. 2, n. 1, p. 37-45, 2010.

HELLMAN, Geoffrey P.; THOMPSON, Frank W. Physicalism: Ontology, determination, and reduction. The Journal of Philosophy, v. 72, n. 17, p. 551-564, 1975.

Physicalist materialism. Noûs, v. 11, n. 4, p. 309-345, 1977.

HELLMAN, Geoffrey. Determination and logical truth. Journal of Philosophy, v. 82, p. 607-616, 1985.

HEMPEL, Carl G. Reduction: Ontological and linguistic facets. In: MORGENBESSER, Sidney; SUPPES, Patrick; WHITE, Morton (Eds.). Philosophy, science and method: essays in honor of Ernest Nagel. New York: St. Martin's Press, 1969. p. 179-199.

. Comments on Goodman's "Ways of Worldmaking”. Synthese, v. 45, n. 2, p. 193-199, 1980.

JACKSON, Frank. Epiphenomenal qualia. Philosophical Quarterly, v. 32, p. $127-$ 136, 1982. 1986.

What Mary didn't know. Journal of Philosophy, v. 83, n. 5, p. 291-295,

From metaphysics to ethics: A defense of conceptual analysis. Oxford:

Oxford University Press, 1998. 
JACKSON, Frank. On ensuring that physicalism is not a dual attribute theory in sheep's clothing. Philosophical Studies, v. 131, n. 1, p. 227-249, 2006.

JUDISCH, Neal. Why 'non-mental' won't work: On Hempel's dilemma and the characterization of the 'physical'. Philosophical Studies, v. 140, n. 3, p. 299-318, 2008.

KIRK, Robert. Raw feeling: A philosophical account of the essence of consciousness. Oxford: Oxford University Press, 1996.

The conceptual link from physical to mental. Oxford: Oxford University press, 2013.

KIM, Jaegwon. Mind in a physical world: An essay on the mind-body problem and mental causation. Cambridge, MA: MIT Press, 1998.

Physicalism, or something near enough. Princeton, NJ: Princeton University Press, 2005.

Philosophy of mind. 2.ed. Boulder: Westview Press, 2006.

KOONS, Robert C.; BEALER, George. The waning of materialism. Oxford: Oxford University Press, 2010.

LEVINE, Joseph. Materialism and qualia: The explanatory gap. Pacific Philosophical Quarterly, v. 64, n. 4, p. 354-361, 1983.

McGINN, Colin. Can we solve the mind-body problem? Mind, v. 98, n. 391, p. 349366, 1989.

MEEHL, Paul; SELLARS, Wilfrid. The concept of emergence. In: FEIGL, Herbert; SCRIVEN, Michael (Eds.). Minnesota studies in the Philosophy of Science. Minessota: University of Minessota Press, 1956. p. 239-252.

MELNYK, Andrew. How to keep the 'physical' in physicalism. The Journal of Philosophy, v. 94, n. 12, p. 622-637, 1997.

Physicalism unfalsified: Chalmers's inconclusive conceivability argument. In: GILLETT, Carl; LOEWER, Barry M. (Eds.). Physicalism and its discontents. Cambridge: Cambridge University Press, 2001. p. 331-349.

. A physicalist manifesto: thoroughly modern materialism. Cambridge: Cambridge University Press, 2003.

MONTERO, Barbara. The body problem. Noûs, v. 33, n. 2, p. 183-200, 1999.

2001.

Post-physicalism. Journal of Consciousness Studies, v. 8, n. 2, p. 61-80,

. What is the physical? In: BECKERMANN, Ansgar; MCLAUGHLIN, Brian (Eds.). The Oxford Handbook of Philosophy of Mind. Oxford: Oxford University Press, 2005. p. 173-188.

MONTERO, Barbara. Psysicalism. In: GARVEY, James. The Continuum Companion to Philosophy of Mind.1.ed. London: Continuum, 2011. p. 92-101. 
MONTERO, Barbara; PAPINEAU, David. A defense of the via negativa argument for physicalism. Analysis, v. 65, n. 3, p. 233-237, 2005.

MSIMANG, Phila M. Problems with the 'physical' in physicalism. South African Journal of Philosophy, v. 34, n. 3, p. 336-345, 2015.

NAGEL, Thomas. Physicalism. Philosophical Review, v. 74, p. 339-356, 1965. 1974.

. What is it like to be a bat? Philosophical Review, v. 83, n. 4, p. 435-450,

NEURATH, Otto. Physicalism. In: COHEN, Robert: NEURATH, Otto (Eds.). Philosophical Papers 1913-1946. Dordrecht: D. Reidel, 1931a. p. 52-57.

Physicalism: the philosophy of the Vienna Circle. In: COHEN, Robert, S.; NEURATH, Otto (Eds.). Philosophical Papers 1913-1946. Dordrecht: D. Reidel, 1931b. p. 48-51.

NEY, Alyssa. Defining physicalism. Philosophy Compass, v. 3, n. 5, p. 1033-1048, 2008.

NIMTZ, Christian; SCHUTTE, Michael. On physicalism, physical properties, and panpsychism. Dialectica, v. 57, n. 4, p. 413-422, 2003.

PAPINEAU, David. The reason why: response to Crane. Analysis, v. 51, n. 1, 3740, 1991.

Philosophical naturalism. Oxford: Blackwell, 1993.

. The rise of physicalism. In: GILLETT, Carl; LOEWER, Barry (Eds.). Physicalism and its discontents. Cambridge: Cambridge University Press, 2001.

PARNIA, Sam. Do reports of consciousness during cardiac arrest hold the key to discovering the nature of consciousness? Medical Hypotheses, v. 69, n. 4, p. 933937, 2007.

PETTIT, Philip. A definition of physicalism. Analysis, v. 53, n. 4, p. 213-223, 1993.

PLACE, Ullin. Is consciousness a brain process? British Journal of Psychology, v. 47, n. 1, p. 44-50, 1956.

POLAND, Jeffrey. Physicalism: the philosophical foundations. Oxford: Clarendon Press, 1994.

Chomsky's challenge to physicalism. In: ANTONY, Louise; HORNSTEIN, Norbert (Eds.). Chomsky and his critics. Hoboken: Blackwell, 2003. p. 29-48.

POPPER, Karl; ECCLES, John. The self and its brain. Berlin, Heidelberg: Springer, 1977.

PUTNAM, Hilary. Psychological predicates. In: CAPITAN, William; MERRILL, Daniel (Eds.). Art, mind, and religion. Pittsburgh: University of Pittsburgh Press, 1967. p. 37-48.

QUINE, Willard V. The scope and language of science. In: QUINE, Willard V. The ways of paradox and other essays. Cambridge, MA: Harvard University Press, 1954. p. $228-245$. 
ROBINSON, William. The hardness of the hard problem. Journal of Consciousness Studies, v. 3, n. 1, p. 14-25, 1996.

RYLE, Gilbert. The concept of Mind. New York: University Paperbacks; Barnes \& Noble, 1949.

SCHAFFER, Jonathan. Is there a fundamental level? Noûs, v. 37, n. 3, p. 498-517, 2003.

SCHEFFLER, Israel. The new dualism: psychological and physical terms. The Journal of Philosophy, v. 47, p. 737-752, 1950.

SCHIFFER, Stephen. Physicalism. Philosophical Perspectives, v. 4, p. 153-185, 1990.

SEARLE, John. The rediscovery of the mind. Cambridge, MA: MIT Press. 1992.

SHELDRAKE, Rupert. Setting science free from materialism. Explore, v. 9, n. 4, p. 211-218, 2013.

SMART, John J. Sensations and brain processes. The Philosophical Review, v. 68, n. 2, p. 141-156, 1959.

. Materialism. The Journal of Philosophy, v. 60, n. 22, p. 651-662, 1963.

. The content of physicalism. Philosophical Quarterly, v. 28, n. 113, p. 339341, 1978.

Physicalism and emergence. Neuroscience, v. 6, n. 2, p. 109-113, 1981.

SPURRETT, David. What physical properties are. Pacific Philosophical Quarterly, v. 82, n. 2, p. 201-225, 2001.

3360, 2015.

Physicalism as an empirical hypothesis. Synthese, v. 194, n. 9, p. 3347-

SPURRETT, David; PAPINEAU, David. A note on the completeness of "physics". Analysis, v. 59, n. 1, p. 25-29, 1999.

STOLJAR, Daniel. Two conceptions of the physical. Philosophy and Phenomenological Research, v. 62, n. 2, p. 253-281, 2001 a.

. The conceivability argument and two conceptions of the physical. Philosophical Perspectives, v. 15, p. 393-413, 2001 b.

Physicalism. London: Routledge, 2010.

Physicalism. In: ZALTA, Edward N. (Ed.) The Stanford Encyclopedia of Philosophy. Disponível em: <https://plato.stanford.edu/entries/physicalism/>. Acesso em: 07 jun. 2016.

STRAWSON, Galen. Realistic monism: why physicalism entails panpsychism. Journal of Consciousness Studies, v. 13, n. 10/11, p. 53-74, 2006.

STURGEON, Scott. Physicalism and overdetermination. Mind, v. 107, n. 426, p. 411432, 1998.

SWINBURNE, Richard. The evolution of the soul. Oxford: Oxford University Press, 1986. 
VAN FRAASSEN, Bas. Science, materialism, and false consciousness. In: KVANVIG, Jonathan (Ed.). Warrant in contemporary epistemology: essays in honor of Alvin Plantinga's theory of knowledge. Lanham: Rowman Littlefield, 1996. p. 149-182.

VAN LOMMEL, Pim. Non-local consciousness: A concept based on scientific research on near-death experiences during cardiac arrest. Journal of Consciousness Studies, v. 20, n. 1/2, p. 07-48, 2013.

VICENTE, Agustín. Current physics and 'the Physical'. British Journal for the Philosophy of Science, v. 62, n. 2, p. 393-416, 2011.

WILSON, Jessica. On characterizing the physical. Philosophical Studies, v. 131, n. 1, p. 61-99, 2006.

WITMER, D. Gene. Physicality for physicalists. Topoi, v. 37, n. 3, p. 457-472, 2016.

ZILIO, Diego. Fisicalismo na filosofia da mente: definição, estratégias e problemas. Ciências \& Cognição, v. 15, n. 1, p. 217-240, 2010.

WORLEY, Sara. Physicalism and the via negativa. Philosophical Studies, v. 131, n. 1, p. 101-126, 2006.

Recebido em: 06-03-2019

Aceito para publicação em: 19-08-19 